\title{
Empedobacter brevis
}

National Cancer Institute

\section{Source}

National Cancer Institute. Empedobacter brevis. NCI Thesaurus. Code C86355.

A species of aerobic, Gram negative, rod or cocci shaped bacterium assigned to the phylum Bacteroidetes. This species is resistant to colistin, hydrolyzes gelatin, does not hydrolyze esculin, urease negative and produces acid from glucose and maltose. E. brevis is involved in nosocomial infections, being a causative agent of meningitis. 